\title{
Pola Makan dan Obesitas berhubungan dengan Riwayat Kejadian Hipertensi di Puskesmas Rawasari
}

\author{
Filius Chandra ${ }^{1}$, Iswanto $^{2}$, Aisah $^{3}$ \\ ${ }^{1,2,3}$ Program Studi S1 Ilmu Gizi STIKes Baiturrahim Jambi \\ Email : aisahilhamsyah@yahoo.co.id
}

Submitted : 14/12/2020

Accepted: 10/09/2021

Published: 15/09/2021

\begin{abstract}
Hypertension is a non-communicable disease (PTM) which is a very serious health problem both in the world and in Indonesia. One sign of hypertension is an increase in blood pressure. Hypertension is called the silent killer, because people with hypertension often show no symptoms. The research objective was to determine the relationship between diet and obesity with the incidence of hypertension at the Rawasari Public Health Center in Jambi City in 2019.This study used a cross sectional design, which was carried out in August 2019, 64 hypertension respondents at the Rawasari Health Center were taken using purposive sampling technique. The research variables were diet and obesity which were analyzed using the chi-square test.This study showed that most respondents had hypertension (92.2\%). most of the diet frequently (51.6\%). and nutritional status (50\%). Chi-square analysis showed that there was a relationship between diet and hypertension $(p=0.016)$ and chisquare analysis showed that there was no relationship between obesity and hypertension ( $p=$ 0.0162). There is no significant relationship between diet and hypertension, and there is no significant relationship between nutritional status and hypertension.
\end{abstract}

Keywords: diet, hypertension, obesity

\begin{abstract}
Abstrak
Hipertensi merupakan salah satu penyakit tidak menular (PTM) yang menjadi masalah kesehatan yang sangat serius baik di dunia maupun di Indonesia. Salah satu tanda penyakit hipertensi adalah terjadinya peningkatan tekanan darah. Hipertensi disebut silent killer, karena penderita hipertensi sering tidak menampakkan gejala. Tujuan peneliti untuk mengetahui hubungan antara pola makan dan obesitas dengan riwayat kejadian hipertensi di Puskesmas Rawasari Kota Jambi. Penelitian ini menggunakan desain cross sectional, yang dilaksakan pada Agustus 2019, dengan 64 responden yang tercatat dengan riwayat hipertensi di Puskesmas Rawasari diambil dengan teknik pengambilan sampel konsekutif sampling. Variabel peneliti ini adalah Pola makan dan obesitas yang di analisis menggunakan uji chi-square. Penelitian ini menunjukkan bahwa sebagian besar responden mengalami hipertensi $(92,7 \%)$. sebagian besar pola makan sering $(51,6 \%)$. dan status gizi tidak normal $(50 \%)$. dari analisis yang dilakukan menunjukkan terdapat hubungan antara pola makan dengan hipertensi $(\mathrm{p}=0,016)$ dan analisi menunjukkan tidak terdapat hubungan antara obesitas dengan hipertensi $(\mathrm{p}=0,0162)$ Terdapat hubungan yang bermakna antara pola makan dengan hipertensi, dan tidak terdapat hubungan yang bermakna antara obesitas dengan hipertensi.
\end{abstract}

Kata Kunci: hipertensi, pola makan, obesitas.

\section{PENDAHULUAN}

Hipertensi merupakan salah satu penyakit tidak menular (PTM) yang menjadi masalah kesehatan yang sangat serius baik di dunia maupun di Indonesia (Anggraini, 2014). Salah satu tanda penyakit hipertensi adalah terjadinya peningkatan tekanan darah. Hipertensi disebut silent killer, karena penderita hipertensi sering tidak menampakkan gejala (Roshifanni, 2016). Seseorang dinyatakan menderita hipertensi bila tekanan darahnya tinggi atau melampaui nilai tekanan darah yang normal yaitu 140/80 mmHg. Penyakit ini telah menjadi masalah utama dalam kesehatan masyarakat yang ada 
di Indonesia maupun di beberapa negara yang ada di dunia (Korneliani, et all. 2012).

WHO (Word Healt Organization) mencatat pada tahun 2012 sedikitnya sejumlah 839 juta kasus hipertensi, diperkirakan menjadi 1,5 milyar pada tahun 2025 atau sekitar $29 \%$ warga dunia terkena hipertensi (WHO, 2009). Berdasarkan Riset Kesehatan kejadian penyakit hipertensi di indonesia adalah 25,8\%, Sedangkan prevalensi penyakit hipertensi pada umur $\geq$ 18 tahun menurut Provinsi Jambi yaitu 24,6\%, (RISKESDAS, 2013). Berdasarkan Riset Kesehatan kejadian penyakit hipertensi di indonesia adalah 34,1\%, Sedangkan prevalensi penyakit hipertensi pada umur $\geq 18$ tahun menurut Provinsi Jambi yaitu 31,7\%, (RISKESDAS, 2018). Berdasarkan data yang diperoleh dari Dinas Kesehatan Kota Jambi, penderita penyakit hipertensi pada tahun 2017, terbanyak di Puskesmas Rawasari Kota Jambi yang berjumlah 3671 orang, menepati peringkat no satu dari dua puluh puskesmas kota jambi (Dinkes Jambi 2017). Beberapa faktor yang dapat menyebabkan seseorang menderita tekanan darah yaitu faktor yang tak dapat di ubah adalah umur, keturunan, jenis kelamin dan faktor yang dapat di ubah adalah olah raga, pola makan, obesitas, minum alkohol, stres (Anise, 018).

Pola makan adalah cara bagaimana kita mengatur asupan gizi yang seimbang serta yang dibutuhkan oleh tubuh. Mengatur pola makan atau disebut diet adalah salah satu cara untuk mengatasi hipertensi tanpa efek samping yang serius, Karena metode pengendaliannya lebih alami, jika dibandingkan dengan obat penurun tekanan darah yang dapat membantu pasiennya menjadi tergantung seterusnya pada obat tersebut. Pola makan yang salah merupakan salah satu faktor resiko yang meningkatkan penyakit hipertensi. Faktor makanan moderen sebagai penyumbang utama terjadinya hipertensi (Mahmudah, et al. 2015).
Obesitas adalah kondisi yang ditandai gangguan keseimbangan energi tubuh, yaitu terjadi keseimbangan energi positif yang akhirnya disimpan dalam bentuk lemak di jaringan tubuh (Hardiansya dan Supriasa, 2014). Menurut Word Health Organization (WHO) tahun 2014, secara umum kegemukan atau obesitas adalah suatu kondisi abnormal yang ditandai oleh peningkatan lemak tubuh berlebihan, umumnya ditimbun di jaringan subkutan, sekitar organ dan kadang terinfiltrasi kedalam organ. Akumulasi lemak tubuh yang berlebih dapat mengakibatkan berbagai gangguan kesehatan.

Pada dasarnya status gizi seseorang ditentukan berdasarkan konsumsi gizi dan kemampuan tubuh dalam menggunakan zatzat gizi tersebut. Status gizi normal menunjukkan bahwa kualitas dan kuantitas makanan yang telah memenuhi kebutuhan tubuh. Seseorang yang berada di bawah ukuran berat badan normal memiliki risiko terhadap penyakit infeksi, sedangkan seseorang yang berada di atas ukuran normal memiliki risiko tinggi penyakit degeneratif. Seperti hipertensi, penyakit jantung koroner, dan diabetes mellitus. Oleh karena itu,diharapkan lebih memperhatikan asupan makanan yang dikonsumsi. Sebaiknya memilih jenis makanan yang sehat dan bergizi sehingga dapat memenuhi kebutuhan gizi seseorang (Pujianti, et al. 2015). Berdasarkan data yang diperoleh dari Dinas Kesehatan Kota Jambi, penderita penyakit hipertensi pada tahun 2017, terbanyak di Puskesmas Rawasari Kota Jambi yang berjumlah 3671 orang, menepati peringkat nomor satu dari dua puluh puskesmas kota jambi (Dinkes Jambi 2017).

Dari uraian di atas peneliti tertarik untuk mengetahui "Hubungan Pola Makan Dan Status Gizi Terhadap Kejadian Hipertensi Di Puskesmas Rawasari Kota Jambi Tahun 2019" 


\section{METODE PENELITIAN}

Sampel pada penelitian adalah pengunjung yang datang di Puskesmas Rawasari Kota Jambi yang tercatat dengan riwayat hipertensi. dengan sampel sebanyak 64 responden. Penelitian ini dilakukan pada bulan Agustus tahun 2019 di Puskesmas Rawasari Kota Jambi. Penelitian ini merupakan suatu penelitian observasional yang menggunakan data primer dengan metode cross sectional dengan menggunakan alat bantu berupa kuesioner food Frequency (FFQ) dan pengukuran status gizi dengan menghitung IMT berdasarkan BB/TB.Peneliti menggunakan informed consent sebagai persetujuan untuk menjadi responden, serta melakukan wawancara

\section{HASIL DAN PEMBAHASAN}

\section{Karakteristik Responden}

Karakteristik responden dibuat bertujuan untuk melihat kondisi umum responden yang diteliti. Karakteristik responden.

Tabel 1 Distribusi frekuensi responden menurut usia Puskesmas Rawasari Kota Jambi Tahun 2020

\begin{tabular}{|c|c|c|}
\hline \multicolumn{1}{|c|}{ Usia } & Jumlah & Persentase $\%$ \\
\hline 45-49 tahun & 27 & 42,2 \\
\hline $60-74$ tahun & 35 & 54,7 \\
\hline $75-90$ tahun & 2 & 3,1 \\
\hline Total & 64 & 100 \\
\hline
\end{tabular}

Berdasarkan tabel 1 dapat dilihat bahwa responden yang terbesar di Puskesmas Rawasari Kota Jambi adalah 6074 tahun sebanyak 35 (54,7\%). Sebagian besar lansia yang menjadi responden ada pada rentang usia 60-74 tahun, yaitu sebanyak 26 orang $(55,3 \%)$, rentang usia 45 59 tahun sebanyak 14 orang $(29,8 \%)$, dan rentang usia 75-90 tahun sebanyak 7 orang $(14,9 \%)$. Seiring peningkatan usia insiden hipertensi juga meningkat, beberapa penelitian menunjukkan seseorang akan terkena hipertensi pada saat berada pada usia 50 tahun keatas. Disamping itu seiring pertambahan usia, kemampuan jantung dalam memompa darah menjadi berkurang $1 \%$ tiap tahunnya (Andriaansz, et al. 2016).

\section{Jenis Kelamin Responden}

Tabel 2 Distribusi frekuensi responden menurut jenis kelamin di Puskesmas Rawasari Kota Jambi Tahun 2020.

\begin{tabular}{|l|c|c|}
\hline Jenis Kelamin & Jumlah & Persentase(\%) \\
\hline Laki-laki & 27 & 42,2 \\
\hline Perempuan & 37 & 57,8 \\
\hline Jumlah & 64 & 100 \\
\hline
\end{tabular}

Berdasarkan tabel 2 dapat dilihat bahwa perempuan yang berkunjung di Puskesmas Rawasari sebagai kasus sebanyak 37 (57,8\%) dan laki-laki sebanyak 27 $(42,2 \%)$.

Berdasarkan penelitian yang dilakukan oleh julius et al (2008). Menunjukkan bahwa dari 337 orang penderita hipertensi didapatkan klasifikasi jenis kelamin terbanyak adalah perempuan yaitu 177 orang $(52,6 \%)$. Bahwa pada perempuan risiko hipertensi akan meningkat setelah masa menopouse yang mempengaruhi penurunan hormon estrogen yang menyebabkan penurunan kadar High Density Lipoprotein (HDL). Kadar kolestrol HDL yang rendah merupakan faktor penyebab dalam terjadinya proses aterosklerosis. Pada premenopause wanita mulai kehilangan sedikit demi sedikit hormon estrogen yang selama ini melindungi pembuluh darah dari kerusakan. Proses ini terus berlanjut dimana hormon tersebut berubah kuantitasnya sesuai dengan umur wanita secara alami, yang umumnya mulai terjadi pada wanita umur 45-55 tahun (Pratiwi, et al. 2013).

Gambaran Pola Makan, Obesitasdan Hipertensi

Gambaran Pola Makan, Obesitas dan Hipertensi di Puskemas Rawasari Kota Jambi Tahun 2020 dapat dilihat pada tabel 3

Tabel 3 Gambaran Pola Makan, Obesitas dan Hipertensi di Puskemas Rawasari Kota Jambi 


\begin{tabular}{c|c|c|c|c|c|c|}
\hline & \multicolumn{2}{c}{ Pola Makan } & \multicolumn{2}{c|}{ Obesitas } & \multicolumn{2}{c|}{ Hipertensi } \\
\cline { 2 - 7 } & $\mathrm{n}$ & $\%$ & $\mathrm{n}$ & $\%$ & $\mathrm{n}$ & $\%$ \\
\hline Normal & 33 & 51,6 & 27 & 42,2 & 13 & 20,3 \\
\hline $\begin{array}{c}\text { Tidak } \\
\text { Normal }\end{array}$ & 31 & 48,4 & 37 & 57,8 & 15 & 79,7 \\
\hline
\end{tabular}

Berdasarkan tabel 3 dari 64 responden dapat diketahui bahwa sebagian besar responden memiliki hipertensi tidak normal sebanyak $51(79.7 \%)$. Faktor usia juga berhubungan dengan terjadinya penebalan dinding pembuluh darah yang berangsur-angsur menyempit dan menjadi kaku, sehingga tekanan darah akan meningkat saat kelenturan pembuluh berkurang, hal ini dimungkinkan karena proses penuaan pada lansia, yang mana kenaikan tekanan darah sistolikk memang cenderung terus meningkat dan tekanan darah diastolik cenderung tetap. (Sulistiyani, et al. 2015)

Berdasarkan tabel 364 responden dapat diketahui bahwa sebagian besar responden memiliki pola makan baik sebanyak $33(51.6 \%)$. Dan responden yang memiliki pola makan tidak baik sebanyak 31 (48.4\%).Hasil penelitian tersebut sejalan dengan penelitian Emerita Stefany (2012)dimana terdapat hubungan pola makan,dengan kejadian hipertensi pada lansia. Hasil penelitian Devi Catur (2015) juga mendukung hasil penelitian ini, dimana terdapat hubungan konsumsi makanan dengan kejadian hipertensi. Pola makan adalah salah satu faktor penyebab terjadinya berbagai penyakit seperti salah satunya adalah hipertensi. Salah satu cara untuk mengurangi terjadinya penyakit hipertensi adalah dengan menjaga pola makan dengan baik yaitu mengurangi asupan banyak lemak dan asupan garam disamping itu perlu meningkatkan makanbuah dan sayur. (Widodo, et al. 2017).

Berdasarkan tabel 3 dari 64 responden dapat diketahui bahwa sebagian besar responden memiliki status gizi obesitas sebanyak 37 (57.8\%) dan memiliki status tidak obesitas sebanyak 27 (42.2\%).
Hasil penelitian ini sejalan dengan penelitian yang dilakukan oleh Manampiring AE dkk (2009), dimana hasilnya menunjukkan ada hubungan yang bermakna antara status gizi lebih dengan kejadian hipertensi. Obesitas merupakan salah satu dari faktor resiko hipertensi. Seseorang yang memiliki berat badan berlebih atau mengalami obesitas akan membutuhkan lebih banyak darah untuk menyuplai oksigen dan makanan ke jaringan tubuhnya, sehingga volume darah yang beredar melalui pembuluh darah meningkat, curah jantung ikut meningkat dan akhirnya tekanan darah ikut meningkat. Selain itu kelebihan berat badan juga meningkatkan kadar insulin dalam darah. Peningkatan insulin ini menyebabkan retensi natrium pada ginjal sehingga tekanan darah ikutnaik. (Ramadhani, et al. 2012).

Hubungan Pola Makan dengan Hipertensi di Puskesmas Rawasari Kota Jambi di Puskesmas Rawasari Kota Jambi Tahun 2020

Salah satu yang paling berpengaruh terhadap timbulnya penyakit adalah pola makan. Pengaturan pola makan bisa mencegah atau menahan agar sakit tidak tambah parah. Mengkonsumsi garam berlebihan menyebabkan haus dan mendorong kita untuk minum

Tabel 4 Distribusi responden menurut hubungan pola makan dengan kejadian hipertensi di Puskesmas Rawasari Kota Jambi Tahun 2020

\begin{tabular}{|c|c|c|c|c|c|c|c|}
\hline \multirow{3}{*}{ Pola Makan } & \multicolumn{4}{|c|}{ Hipertensi } & \multirow{2}{*}{\multicolumn{2}{|c|}{ Jumlah }} & \multirow{3}{*}{$p$-value } \\
\hline & \multicolumn{2}{|c|}{$\begin{array}{c}\text { Tidak } \\
\text { Hipertansi }\end{array}$} & \multicolumn{2}{|c|}{ Hipertensi } & & & \\
\hline & $\mathrm{N}$ & $\%$ & $\mathrm{~N}$ & $\%$ & $\mathrm{n}$ & $\%$ & \\
\hline Tidak Baik & 0 & 0 & 33 & 87,9 & 33 & 100 & \multirow{3}{*}{0,016} \\
\hline Baik & 5 & 16,1 & 26 & 83,9 & 31 & 100 & \\
\hline Jumlah & 5 & 7,8 & 59 & 92,2 & 64 & 100 & \\
\hline
\end{tabular}

Tabel. 4 diatas menunjukkan bahwa dari 33 responden pola maPolkan sering sebanyak $4(12,1 \%)$ dengan tidak hipertensi, dan sebanyak $29(87,9 \%)$ dengan hipertensi. 
dari 31 responden dengan pola makan tidak sering sebanyak $9(29,0 \%)$ dengan tidak hipertensi, dan sebanyak $22(71,0 \%)$ dengan hipertensi. Hasil uji statistik diperoleh $p$ value 0,093 yang berarti $p>0,05$. Maka Ho diterima sehigga Hasil ini menunjukkan bahwa tidak ada hubungan yang bermakna pola makan dengan hipertensi. Menurut penelitian yang sama dilakukanoleh Dalyoko. menyimpulkan bahwa pola makan yang berhubungan dengan kejadian hipertensi pada lansia adalah $p$-value = 0,016 . Maka ada hubungan yang signifikan antara pola makandengan pengedalian hipertensi pada lansia.Menurut penelitian yang dilakukan oleh Susriyanti menunjukkan bahwa pola makan berhubungan dengan kejadian hipertensi lansia dengan $P$-value sebesar 0,017

Namun hasil penelitian dilakukan oleh Siringoringo menunjukkan bahwa tidak adahubungan pola makan dengan kejadian hipetensipada lansia dengan nilai $P$-value sebesar 0,054,maka Ha ditolak. Menurut asumsi peneliti, bahwa bagi lansia yang mengalami hipertensi banyak disebabkan oleh pola makanan yang tidak ada aturan atau tidak sesuai asupan, untuk itu lansia harus lebih memperhatikan dan mengatur pola makan yang bergizi buat kesehatannya.

Hubungan Obesitas dengan Hipertensi di Puskesmas Rawasari Kota Jambi di Puskesmas Rawasari Kota Jambi Tahun 2020

Berat badan yang berlebih akan membuat seorang susah bergerak dengan bebas, jantungnya harus bekerja lebih keras untuk memompa darah agar bisa menggerakkan beban berlebihan tersebut. Karena itu obesitas termasuk salah satu faktor yang meningkatkan risiko hipertensi dan serangan jantung. (Aquarista, dkk, 2017).

Tabel 5 Distribusi responden menurut hubungan obesitas dengan kejadian hipertensi di Puskesmas Rawasari Kota Jambi Tahun 2020

\begin{tabular}{|c|c|c|c|c|c|c|c|}
\hline \multirow{3}{*}{ Obesitas } & \multicolumn{4}{|c|}{ Hipertensi } & \multirow{2}{*}{\multicolumn{2}{|c|}{ Jumlah }} & \multirow{3}{*}{$P$-value } \\
\hline & \multicolumn{2}{|c|}{ Normal } & \multicolumn{2}{|c|}{$\begin{array}{l}\text { Tidak } \\
\text { Normal }\end{array}$} & & & \\
\hline & $\mathrm{n}$ & $\%$ & $\mathrm{n}$ & $\%$ & $\mathrm{~N}$ & $\%$ & \\
\hline $\begin{array}{c}\text { Tidak } \\
\text { Obesitas }\end{array}$ & 1 & 3,1 & 31 & 96,6 & 32 & 100 & \multirow{3}{*}{0,162} \\
\hline \multirow[t]{2}{*}{ Obesita } & 4 & 12,5 & 28 & 87,5 & 32 & 100 & \\
\hline & 5 & 7,8 & 59 & 92,2 & 64 & 100 & \\
\hline
\end{tabular}

Tabel. 5 diatas menunjukkan bahwa dari 27 responden status gizi tidak obesitas dengan tidak hipertensi sebanyak $2(5,5 \%)$ dan status gizi obesitas dengan hipertensi sebanyak $25(92,6 \%)$ dan statu gizi obesitas 37 responden. responden obesitas dengan tidak hipertensi sebanyak $11(7,5 \%)$ dan responden obesitas dengan hipertensi sebanyak 26 (70,3\%). Hasil uji statistik diperoleh $p$-value 0,028 yang berarti $\mathrm{p}<$ 0,05., hal ini berarti bahwa ada hubungan yang secara statistik bermakna antara status gizi dengan kejadian hipertensi.

Hal ini sejalan dengan penelitian yang dilakukan oleh Hendra (2013), yang menyatakan ada hubungan yang bermakna antara Obesitas dengan kejadian hipertensi dengan nilai $p$-value $0,000<0,005$ Risiko relatif untuk menderita hipertensi pada orang-orang gemuk 5 kali lebih tinggi dibandingkan dengan seorang yang badannya normal. Penderita obesitas atau kelebihan berat badan, resiko menderita hipertensi lebih besar dibandingkan orang yang kurus. Obesitas atau kegemukan merupakan faktor resiko yang sering dikaitkan dengan hipertensi. Resiko terjadi hipertensi pada individu yang semula nonmortensi bertambah dengan meningkatkan berat badan. Individu dengan kelebihan berat badan $20 \%$ memiliki resiko 3-8 kali lebih tinggi dibandingkankan dengan individu dengan berat badan normal. (Pratiwi, et al. 2013).

\section{SIMPULAN}

Berdasarkan hasil penelitian dan pembahasan maka disimpulkan bahwa Terdapat hubungan antara pola makan 
dengan hipertensi di Puskesmas Rawasari Kota Jambi dan tidak adanya hubungan antara status gizi dengan hipertensi di Puskesmas Rawasari Kota Jambi.

\section{SARAN}

Kepada masyarakat sebaiknya memilih jenis makanan yang sehat dan bergizi sehingga dapat memenuhi kebutuhan gizi seimbang. Kepada pihak Puskesmas dapat meningkatkan edukasi khususnya pengaturan pola makan/diet hipertensi.

\section{DAFTAR PUSTAKA}

Almatsier, S. (2004). Penuntun Diet Edisi Baru. PT Gramedia Pustaka Utama. Jakarta

Anise. (2018). Mencegah dan Mengatasi Penyakit Degeneratif Dengan Perilaku dan Pola Hidup Moderen Yang Sehat. AR-RUZZ MEDIA.Yogyakarta.

Archilona, Z.Y., Nugroho, h.k., dan Puruhita N. (2016). Hubungan Antara Indeks Massa Tubuh (IMT) Dengan Kadar Lemak Total. Jurnal Kedokteran Diponegoro. 5 (2) April 2016:122131.

Aquarista, M.F., dan Hadi Z. (2017). Hubungan Kebiasaan Olahraga Dan Status Gizi Dengan Kejadian Hipertensi Pada Pasien Yang Berobat Jalan Di Puskesmas Kelayan Dalam Banjarmasin. Jurnal Ilmiah Pendidikan dan Sosial. 3 (2).

Dewanti, (2008). Hubungan PolaMakan, Aktivitas Fisik, dan Perubahan Tekanan Darah padaLansia Penderita Hipertensi diPuskesmas Melati II, Sleman. Universitas Gajah Mada.

Dinkes. (2017). Provinsi Jambi. Jakarta

Husnah, dkk. (2012). Gambaran Pola Makan Dan Status Gizi Mahasiswa Kuliah Klinik Senior (Kks) Di Bagian Obsgyn Rsud Dr. Zainoel Abidin Banda Aceh. Jurnal Kedokteran
Syiah Kuala, Aceh. 12 (1) April 2012.

Korneliani, K., dan Meida D. (2012). Obesitas Dan Stress Dengan Kejadian Hipertensi. Fakultas Ilmu Kesehatan Universitas Siliwangi Tasikmalaya. Indonesia. Jurnal Kesehatan Masyarakat. 7(2) (2012) : 117-121

Lewis, Sharon, M., Margaret, M. H.,\& Shanon R. D. (2000). Medikal Surgicl Nursing Assesment and Management of Clinical Problems. St. Louis, Missouri: Mosby Inc.

Mamahit, M.L., dan Onibala, M.F. (2017). Hubungan Pengetahuan Tentang Diet Garam Dengan Tekanan Darah Pada Lansia Di Puskesmas Bahu Kota Manado. Univrsitas Sam Ratulangi Manado. Jurnal Keperawatan 5(1) Februari 2017.

Mahmudah, S., Maryusman, T., Arini, A.F., dan Malkan, I. (2015). Hubungan Gaya Hidup Dan Pola Makan Dengan Kejadian Hipertensi Pada Lansia Di Kelurahan Sawangan Baru Kota Depok Tahun 2015. Fakultas Ilmu Kesehatan. Jakarta. 7 (2) Agustus 2015.

Miko, A., dan Dina B.P. (2016). Hubungan Pola Makan Pagi Dengan Status Gizi Pada Mahasiswa Poltekkes Kemenkes Aceh. Jurnal Action: Aceh Nutrition Journal, November $2016: 1$ (2) : 83-87.

Mahmudah, S., Maryusman, T., Arini, A.F., dan Malkan, I. (2015). Hubungan Gaya Hidup Dan Pola Makan Dengan Kejadian Hipertensi Pada Lansia Di Kelurahan Sawangan Baru Kota Depok Tahun 2015. Fakultas Ilmu Kesehatan. Jakarta. 7(2) Agustus 2015.

Pudiastuti, R. D. (2013). Penyakit-penyakit mamatikan. Yogyakarta: Nuha Medika

Pujiati, Arneliwati, dan Rahamalia, S. (2015). Hubungan Antara Perilaku 
Makan Dengan Status Gizi Pada Remaja Putri. Program Studi Ilmu Keperawatan Universitas Riau. 2 (2) Oktober 2015.

Riskesdas. 2013. Badan Penelitian Pengembangan Kesehatan Kemenrian Kesehatn RI 2013. Riset Kesehatan Daerah. Jakarta

Roshifanni, S. (2016). Risk oh hypertension in people with poor sleep pattern (Study in Puskesmas Tanah Kalikedinding Surabaya). Universitas Airlangga Surabaya. Indonesia. 4 (3) : 408-419

Supariasa, dkk. (2002). Penilaian Status Gizi. Jakarta : Penerbit Buku Kedokteran EGC.

Triyanto, E. (2014). Pelayanan Keperawatan Bagi Penderita Hipertensi Secara Terpandu. Graha Ilmu.Yogyakarta

WHO. (2009). Report of Hypertensions. WHO/CDS/RBM/2001.35 Geneva 28-30 March 2009. 